\title{
Internationalizing the Curriculum: Faculty and Student Perspectives
}

\author{
Courtney Hartzell \\ Boston College, USA
}

\begin{abstract}
Faculty and student mobility are one component of internationalization, but one that often receives most of the attention, while only reaching a small percentage of students and staff. Universities around the world have embarked on individual journeys in internationalizing the curriculum (IoC) and Internationalization at Home (IaH). With the support of technology, international and intercultural learning is possible for all students. Online projects create opportunities for innovative ways to foster intercultural competence, interdisciplinary and transformative learning, without the constrictions of space or time. At the culmination of the German Rector's Conference in Germany, the University of Goettingen received funding to initiate its first pilot projects of IoC through digitally supported teaching and learning projects. This paper describes a qualitative case study conducted in the fourth year of the pilot projects. It will examine the perceived value that IoC has added in regard to the unique program of study, the curriculum, and individual learning for faculty and students. For the purpose of this research, individual interviews with faculty and students were transcribed and analyzed using a phenomenographic approach. The results of the case study could be significant for reforming institutional teaching and learning policies, sustainability proposals, and as a beacon for other institutions.
\end{abstract}

\section{Introduction}

Internationalization of the curriculum, IoC, is defined by Leask [1] as, "...the process of incorporating international, intercultural and global dimensions into the content of the curriculum as well as the learning outcomes, assessment tasks, teaching methods and support services of a program of study." Internationalizing the curriculum is multifaceted and includes recognizing potentials within the construct of a curriculum, classroom, institution, region, and the world [2]. Leask outlines a theoretical framework which has transdisciplinary knowledge at the core, wrapped in layers of contextual frames: institutional, local, national and regional, and global. Global contexts reside at the outer layer of the model, serving to prove that it is an influential layer which embodies all other components. Student learning, program development, and professional development are intertwined and are integral parts of the contextual layers [2].
As De Wit and Leask [6] argue, internationalization should happen through academia, and not left as a separate responsibility for international offices on campus. Mobility of faculty and staff can be seen as a way to internationalize campuses, but will arguably only reach a limited number of students [3] While programs like ERASMUS provide many students in the European Union the opportunity to study abroad, around $80 \%$ of students will not participate in study abroad programs [6]. Internationalization at Home (IaH) is seen to complement outbound mobility, in that the experiences gained whilst on campus can promote and enhance outbound mobility in dynamic ways [3].

The curriculum is one significant space in which educators and students alike, converge for the shared purpose of expanding knowledge. Curriculums can be used as platforms for faculty to incorporate components that will allow students to engage with each other, as well as serve as diverse, collaborative, shared-learning platforms, that promote critical thinking and self-reflection. Internationalization of the curriculum (IoC), sometimes referred to as comprehensive internationalization, asserts that the curriculum is comprised of the formal, informal, and hidden curriculum [2]. This study will be focused on the formal curriculum, which encompasses the explicit, planned syllabus and learning outcomes, as well as the hidden curriculum, referring to implicit skills, messages, and expectations [2].

The German Rector's Conference (HRK) has made internationalization a national priority, in part due to the demands of European benchmarks, and also their desires to stay competitive within the global landscape [12]. HRK outlines themes of importance within the initiative which include but are not limited to: digitization, mobility of researchers, faculty and staff, networking, visibility, and campus culture [12]. In 2015, the University of Goettingen was one of many institutions within Germany that was selected to embark on the government-funded initiative, which aims at internationalizing the curriculum through digitally supported teaching and learning projects.

The University of Goettingen's approach to IoC is unique in that every project has a distinctive component of digitalization [4]. The HRK initiative has been instrumental for encouraging faculty members of diverse disciplines to engage in Leask's reflective model, and consult with specialists on how to design and implement digitally supported teaching and learning models within their curriculum. 
Interested members of faculty must submit a proposal which states their intention and plan for internationalizing the curriculum through digitally supported teaching and learning projects, and from there the proposal is allotted a budget and plan depending on the scope. The projects thus far have included work in fields such as theology, world literature, agriculture, and more [4].

A dedicated team of experts regularly consult with faculty and staff involved, and not only assist in instructional design, but also in creating high-quality, innovative, digital content that is implemented and archived for classroom modules [4]. HRKEXPERTISE Internationalisation will continue to fund the University of Göttingen until 2020, which places greater emphasis on assessing qualitative elements now, so that sustainability and program continuation can be considered from multiple perspectives.

Digitization has been the chosen medium for such projects, as recent developments in Information Technology create opportunities for innovative ways to foster intercultural competence, interdisciplinary and transformative learning, without the constrictions of space or time. Within this framework, the responsibility of engaging in internationalization shifts from the focus of student mobility schemes, to a curriculum-oriented focus with learning objectives that affect all students involved [5]. Virtual internationalization offers possibilities of multimodal dimensions for engaging learners and facilitators, and is not bound by tasks or learning objectives, but broadly by more implicit collaborations between faculty, students, and institutional partnerships [8]. Technological platforms are used as interfaces between all involved and are used to stimulate intercultural, transformative learning.

The faculty play an integral role in internationalizing the curriculum, as they reside as the connection between the curriculum and students. Therefore, the perspective the faculty lend to this ongoing process is invaluable; without the buy-in of the faculty involved, the sustainability and integrity of the entire project would be jeopardized. The support of the faculty can be hindered by dogmatism and the presumption that 'teachers know best' and, therefore, need not change the intended curriculum [7]. As Grunzweig [7] notes, transnational dialogue is difficult to measure. Faculty can be held accountable by national and institutional assessments, but in regard to the 'hidden' curriculum [2] maintaining a record of student and faculty feedback could help in bringing to light commonalities where the efforts are succeeding, issues that require more attention, and nuances that lead to future discoveries.

The University of Goettingen is approaching its final year funded by the national initiative. Therefore, it is increasingly urgent to record detailed accounts of the projects completed and in-process till date, as well as the qualitative impacts they have had on faculty and students. What is missing from the literature so far is an empirical study evaluating the University of Goettingen's faculty and student perceptions on the value added, specific to their program of study, the curriculum, and to their overall personal development. Student and faculty perceptions are necessary to ignite systemic development that will influence knowledge dissemination and institutional change, as well as contribute to ongoing studies evaluating student and faculty development.

\section{Method}

At the University of Goettingen, many members of faculty and staff have actively participated in the ongoing process of IoC through digitally supported teaching and learning projects. This study focuses on two central research questions within the scope of IoC through digitally supported teaching and learning projects:

1. What is the perceived added value to the curriculum?

2. What is the perceived added value to the specific program of study?

The data was collected entirely from faculty, supporting staff, and students at the University of Goettingen that were actively engaged either as educators or learners in IoC projects. The thirteen participants represent seven different projects. The on-site coordinator of all IoC projects is a scholarpractitioner who works alongside a team of experts to help facilitate and support faculty and staff involved. The University of Goettingen is a leading, public research institution in Goettingen, Germany. The institutional review board approved this study and is GDPR compliant.

The thirteen participants represent seven disciplines across the social sciences, science, and humanities, and included five students, four coordinating staff, and four faculty members. For the purpose of this study, all faculty and staff will be referred to as faculty. Around one third of participants were international, and the rest were domestic. The interview questions were structured for faculty and semi-structured for students. In order to preserve anonymity, specific project titles and pronouns of participants will not be used. Each interview was recorded and transcribed using a phenomenographic approach [9]. Participants were asked to describe their involvement in and a description of their projects, their understanding of the theoretical foundation of IoC, and about the value of digitally supported teaching and learning projects in relation to the curriculum and to their program of study. The composition of participants was almost exactly split between men and women. 


\subsection{Limitations}

Though the invitation to participate was sent to over forty faculty members that have been involved since the first pilot projects, less than fifteen responded. The time frame of the sessions coincided with a semester break, which is one possible reason for the low response rate. In addition, the interviews were conducted entirely by using an online video conferencing platform, which could have deterred faculty and students who did not have stable internet connections, or were not comfortable using such platforms. It is also possible that the non-responsive faculty and students had mixed experiences and were reluctant to participate. The researcher had a very brief introduction to the potential participants, so the unfamiliarity between researcher and participants could be another reason for low interest in participating.

\section{Results}

Faculty and students alike had comprehensive ways of explaining IoC. Since IoC serves as the theoretical framework for all of the projects embarked on, it was important to assess participants' understanding of IoC. The quotes below showcase only a few of the participants' responses, but it is worth noting that every participant was able to describe IoC in a way that reflects Leask's (2015) aforementioned definition. When asked about what IoC means, students and faculty described it as;

"Providing diverse perspectives on the topic; challenging previously accepted norms within the topic; examining how different communities around the world view the topic, and what it means to their communities."

"It broadens your horizons. It makes academia better. Not only to look at one place and explain the whole world. And of course, it adds to things like...realizing kind of the scope and also limitations of your thoughts."

"...to include the world view or the culture of international students .... into teaching and learning and to open up the teaching (of) foreign aspects so that students from all backgrounds can identify themselves with what they're taught. And of course, there's also the dimension of including students from different backgrounds and nationalities into a community of students that's also internationalized, and making students mobile, both physically, and in their mind."

"Internationalization means to me that I can have different perspectives without being in the universities in England or Sweden."

"It's a stay abroad light"

"...inclusive for everyone...internationalizing means bringing everyone together."
While student interpretations focused mostly on the value of diverse perspectives that IoC brings, emphasizing intercultural dimensions, faculty described IoC in terms of its academic potential. Interpretations largely reflect the participants' identity; faculty, responsible for setting academic outcomes, creating content, and administering assessments, were inclined to highlight how IoC has benefited academically, whereas students, recipients of such, are immersed in the student experience and expressed IoC in terms of its holistic, social and personal benefits.

Data from the interviews is represented in the form of a Table below. A discussion of the themes that arose is presented after the summary of the findings from the table.

The bold text in Table 1 highlights areas that were the same for faculty and students, in which personal growth and subject knowledge had the most overlap. Faculty often reflected on the value gained for themselves in terms of their professional development, whereas students spent more time reflecting on how IoC through digitally supported projects has benefited them on a personal level.

Professional development and digitalization were areas of the most divergent responses. However, it could be postulated that professional development is relative to the participant's identity. For students, professional development was observed in the form of academic skills in writing, building better arguments, and gaining insight into the industry in international contexts. However, professional development for faculty was more extensively articulated in relation to their identity as a professor. The second area of discrepancy reveals a difference in perception of digitalization between faculty and students. It could be possible that digitalization is more pertinent to traditional-aged students, as it has been an inherent part of their generation compared to faculty, amounting to a more optimistic, constructive perception. Students praised the flexibility that digitalization gives them in regard to accessing it when they choose to, including re-watching lectures. The ability to apply the content and perspectives gained in one class to other contexts, in this example, a different class, lends to transformative learning.

Faculty, on the other hand, were mainly skeptical about the impact of digitalization and the costs involved. IoC initiatives were not seen to be the problem in essence, rather the role of digitalization and its impact. The cost to maintain an equipped studio that is able record high quality videos was scrutinized, and a more affordable alternative was alluded to by one participant, “...we have this fancy studio and I don't know how much money was spent on making those kind of videos and so on, but considering the fact that people make decent iPhone movies I guess everything's possible." 
Table 1. Data from the interviews

\begin{tabular}{|c|c|c|c|c|}
\hline & Faculty & Student & Faculty Quotes & Student Quotes \\
\hline Personal Growth & $\begin{array}{l}\text {-gain different perspectives } \\
\text { - better understand own } \\
\text { bias } \\
\text { - able to work as part of a } \\
\text { diverse team }\end{array}$ & $\begin{array}{l}\text { - more tolerant of different } \\
\text { perspectives } \\
\text { - better understand own } \\
\text { bias } \\
\text { - reflect on own culture and } \\
\text { integrate new perceptions } \\
\text { - able to work as part of a } \\
\text { diverse team } \\
\text { - gain different } \\
\text { perspectives }\end{array}$ & $\begin{array}{l}\text { "What I've gained now is } \\
\text { interacting with the } \\
\text { different people that we've } \\
\text { had" (in reference to hosting } \\
\text { guest lecturers) (900) } \\
\text { "These social skills to work } \\
\text { in an international team is } \\
\text { something that everybody } \\
\text { should be able to do when } \\
\text { they graduate from a } \\
\text { university today." (120) }\end{array}$ & $\begin{array}{l}\text { "For some it's quite } \\
\text { obvious what this } \\
\text { broadening } \\
\text { understanding the others has } \\
\text { brought, and deeper and } \\
\text { more tolerant discussions" } \\
(220) \text { "...also try to give us as } \\
\text { students a broader } \\
\text { perspective, kind of helping } \\
\text { us move beyond } \\
\text { provinciality and think more } \\
\text { globally" (250) }\end{array}$ \\
\hline Subject Knowledge & $\begin{array}{l}\text { - broader content range } \\
\text { - new areas of research } \\
\text {-interdisciplinary } \\
\text { growth } \\
\text { - build shared databases for } \\
\text { future research } \\
\text { - reflect on bias in subject } \\
\text { - dispel traditional } \\
\text { hierarchies }\end{array}$ & $\begin{array}{l}\text { - broader content range } \\
\text {-interdisciplinary } \\
\text { growth } \\
\text { - reflect on bias in subject } \\
\text {-dispel traditional } \\
\text { hierarchies }\end{array}$ & $\begin{array}{l}\text { "I think partly it's eye } \\
\text { opening and partly it is } \\
\text { being provoked to think } \\
\text { more about it, to try to } \\
\text { understand it better, to } \\
\text { discuss it." (900) } \\
\text { "We want to establish a } \\
\text { database where they will be } \\
\text { filled with information from } \\
\text { our colleagues that do the } \\
\text { videos, but also with } \\
\text { information from the } \\
\text { students." }(800) \\
\text { "...these videos so far are } \\
\text {...much more detailed than } \\
\text { what I could offer" }\end{array}$ & $\begin{array}{l}\text { "...different kinds of } \\
\text { diversity aspects of different } \\
\text { cultures and different } \\
\text { people. Not only out of our } \\
\text { perspective but also...to } \\
\text { learn about other } \\
\text { perspectives, other ways to } \\
\text { think about it and to analyze } \\
\text { it. It's really important for } \\
\text { my field of study." (140) }\end{array}$ \\
\hline Professional Development & $\begin{array}{l}\text { - expand academic } \\
\text { communities } \\
\text { - practice new methods of } \\
\text { research } \\
\text { - update pedagogy }\end{array}$ & $\begin{array}{l}\text { - able to build well rounded } \\
\text { arguments } \\
\text { - more confident writers } \\
\text { - insight into } \\
\text { industry in international } \\
\text { contexts }\end{array}$ & $\begin{array}{l}\text { "There is a lot of } \\
\text { networking being done in } \\
\text { the background where the } \\
\text { scientists are getting closer } \\
\text { to each other and actually } \\
\text { realizing what's the other } \\
\text { one's actually doing." }(800) \\
\text { "...my lecture will causally } \\
\text { be peer reviewed by other } \\
\text { scientists with PhD's... the } \\
\text { quality of your lecture } \\
\text { improves"(100) }\end{array}$ & $\begin{array}{l}\text { "Cross cultural } \\
\text { management, a social } \\
\text { science, for example, is } \\
\text { more important because we } \\
\text { live in a globalized world } \\
\text { and almost every company } \\
\text { is international or acts } \\
\text { international, all around the } \\
\text { world. So, it's more like a } \\
\text { basic need, or a base that } \\
\text { you have to have as an } \\
\text { employee to get a job, or } \\
\text { maybe even to be a better } \\
\text { employee." (140) }\end{array}$ \\
\hline Digitalization & $\begin{array}{l}\text { - skeptical about its impact } \\
\text { and function } \\
\text { - concerned about the cost of } \\
\text { upkeep } \\
\text { - enjoyed creating shared } \\
\text { database } \\
\text { - a resource for other } \\
\text { classes }\end{array}$ & $\begin{array}{l}\text { - eager for more expansion } \\
\text { - expressed concerns about } \\
\text { accessibility } \\
-\quad \text { readily gave } \\
\text { recommendations for } \\
\text { improvements } \\
\text { - allowed for flexibility in } \\
\text { schedules and location } \\
\text { - a resource for other } \\
\text { classes }\end{array}$ & $\begin{array}{l}\text { "... think that there's no } \\
\text { real substitute for face to } \\
\text { face teaching. The other } \\
\text { thing I feel about how } \\
\text { we've approached e- } \\
\text { learning is the amount of } \\
\text { time and effort and work } \\
\text { that's invested into creating } \\
\text { these e- learning units is } \\
\text { actually fairly inefficient, } \\
\text { and if the university has } \\
\text { money to spend on these } \\
\text { things, it might be better } \\
\text { spent bringing scholars into } \\
\text { teach or sending scholars or } \\
\text { students abroad." (500) }\end{array}$ & $\begin{array}{l}\text { "...we also hear that about } \\
\text { the farmers in India for } \\
\text { instance that normally we } \\
\text { don't even think of. I think } \\
\text { this is one aspect for where } \\
\text { digitalization can really } \\
\text { help, of course it does not } \\
\text { replace face to face } \\
\text { meeting, but it } \\
\text { approximates it." (250) }\end{array}$ \\
\hline
\end{tabular}


The idea of 'out sourcing' faculty for the purpose of creating a video was seen as a short term, nonimpactful practice, to which a few faculty members said can be used in ways that perpetuate neocolonialism in academia; "...you actually outsource it to international people who give their perspective, which is often of course developed in relation to global northern concepts because you can't escape them if you want to have a career in academia." The themes that arose are categorized as follows: bridging students and faculty from diverse backgrounds, expanding knowledge while crossing borders, working towards global citizenship, and sustainability.

\subsection{Bridging students and faculty from diverse backgrounds}

Participants expressed that more diversity in students and faculty complement IoC, as diversity significantly contributes to personal and academic discussions, and faculty and students can act as in class' resources. Both students and faculty noticed that since the commencement of IoC projects, students have become more confident in academic writing, more tolerant in discussions, and able to build better arguments that consider multiple perspectives.

Students and faculty also alluded to the benefit that gaining different cultural perspectives was necessary for working in teams and is a crucial skill for their professional careers. For faculty, working in teams translated to working with other international scholars, "...the process of dealing with professors from different backgrounds and how they communicate, and what their understanding of internationalization are." The relationships built between faculty and students, and students with each other were seen to be valuable and diverse.

\subsection{Expanding knowledge while crossing borders; Discipline specific growth}

The value of being able to reflect on commonalities and differences within a specific field of study, in various cultural and regional contexts leads to gaining new perspectives and insights into program specific foundational theories. "There are some rice genotypes in China and productivity in China is really high. This was new to me because my country likes rice more than wheat. So maybe in the future if I go back to my country, I will suggest this to bring this genotype from China because they have the highest productivity." By uncovering topics not included in former curricula, faculty are able to broaden the scope of what is being taught, while at the same time maintaining quality and achieving measurable learning outcomes. Students benefit by drawing comparisons from the material presented in relation to their own experience.

Since embarking on the process of IoC, faculty emphasized how they were able to create compilations of video lectures given by international experts in areas that could not previously be covered in such detail, thus expanding the breadth of specialized material available for students. For some, this took form in the opportunity to challenge traditional neo-colonial hierarchies that are transposed within academia and led students to reflect on implications of "west versus the rest" and the power of the global north.

The digital component of such projects allowed faculty to curate content for use in other courses, and even resulted in a resource used between institutions. Students indicated that some of this content made such an impression that they continued to reflect on it and apply concepts to other courses, which highlights the transformative effect of IoC [10]

International peers wanted to participate in content creation regardless of the allure of a possible publication, which demonstrates the power of transformative mutuality in IoC. Other participants echoed this by adding that the initiative has helped force scholars to update their research and pedagogy, as well as add to the field by providing new, collaborative research.

\subsection{Working towards global citizenship}

A common theme in all participants circled around the development of a new cultural community throughout IoC projects; “...it's also about establishing the exchange between the students among themselves and the lecturers and so on to create this sort of international atmosphere." IoC forges intellectual communities that develop intercultural competence through direct and indirect interaction with people and content.

A key part of this process is self-reflection, and enabling students to realize how they play a part in our interconnected world [11]. It is the intent of this initiative that this "brings more understanding for people and societies elsewhere," and better prepares students and faculty for being responsible, globally aware citizens.

\subsection{Encouraging Sustainable Practices}

As one participant stated, the number of domestic students in Germany is expected to decrease in the coming years, making the reality of internationalization a necessity for growth. The potential increase in international students at the University of Goettingen gives further reason to consider sustainable strategies in IoC. 
Though conducting classes in English does not mean that a curriculum is internationalized, it is one aspect that some faculty believe to be a possible barrier to inclusivity, both in the range of resources and in reaching the potential student body. The notion to expand current courses conducted in English has started to gain momentum with the advent of IoC initiatives, however, some participants recalled other faculty on campus expressing a lack of interest or urgency to begin internationalizing their curriculum. It is crucial to note that even if a class is conducted in English, if the curriculum is not internationalized, the language of instruction is not the pertinent issue [11].

Due to the limitations of select projects, short time frames, and skepticism of digitalization, faculty members expressed doubts regarding the long-term sustainability of current IoC initiatives and surmised that projects were only able to make surface level effects. "So, you have your little project...but it's never something that reaches the bases. It's never something that can change the structure the from within. It's always just scratching a bit on top, adding something nice here or there because the time frame is too short for that." Presumably, deeper, not broader, impacts engender systemic change.

Engaging in long term collaborations both internally and externally, and being more visible about current projects were proposed by faculty as a solution to gaining attraction on campus, which could contribute to a holistic approach in institutional change.

\section{Discussion and Conclusion}

Case studies, such as this, highlight similarities and discrepancies that could point to gaps in previous literature, and reaffirm theories that have been put into action. The discrepancies between faculty and students regarding the perceived value of IoC indicate that the perception of digitalization was a point of contention. The positive perceptions shared by faculty and students demonstrate that IoC offers transformative personal, professional, and academic benefits.

Without the national support of the German Rector's Conference, this study and discussion might not have been possible. Institutions such as the University of Goettingen, that have gained government support in IoC initiatives and are able to interpret internationalization at home according to their own context, have made great strides in the ongoing worldwide effort of supporting internationalization. The pilot projects that began in 2015 have undoubtedly already started to transform the campus community and everyone involved.

As the findings from this study suggest, continued diversity in students and faculty, and faculty development through IoC, are two complementary sources of great potential that could contribute to holistic changes in internationalization on campus. Sustainability should also be discussed in future projects, taking into consideration fluctuations in funding, advancements in online learning, institutional and national support, and diverse student and faculty perceptions.

A possible future study could investigate sustainable features of similarly oriented institutions that have spent three years or more on internationalizing their curricula to see what aspects have been successful thus far and what challenges remain. Other institutions looking to embark on internationalizing their curriculum can use this report as an indicator of some of many faculty and student perspectives concerning the value $\mathrm{IoC}$ has added.

\section{Acknowledgements}

I would like to acknowledge Dr. Hans de Wit, Dr. Betty Leask, and Dr. Tanja Reiffenrath for their ongoing encouragement and guidance.

\section{References}

[1] Leask, B. 2009, p. 209 Leask, B. (2013). Internationalization of the Curriculum and the Disciplines: Current Perspectives and Directions for the Future

[2] Leask, B. (2015). Internationalizing the curriculum. (pp. 1-42). London: Routledge.

[3] Beelen, J. (2013). Internationalisation at Home: History and conceptual notions. In: Chapter II. Guide of good practices Tempus Corinthiam. (pp. 1-2). Retrieved from: https://www.academia.edu/10267813/Internationalisation at_Home_History_and_conceptual_notions

[4] Georg-August-Universität. (2019). The Goettinger Model. Retrieved from: https://www.unigoettingen.de/en/586285.html

[5] Bruhn, E. (2017). Towards a framework for virtual internationalization. International Journal of E-Learning \& Distance Education, v32 n1 2017. Retrieved from: https://eric.ed.gov/?id=EJ1159898

[6] Leask, B., De Wit, H. (2013). Internationalization of the Curriculum and the Disciplines: Current Perspectives and Directions for the Future.

[7] Grunzweig, W. (2006). My home is my classroom: A critical approach to Internationalization at Home. In: Teekens, H. (Ed). Internationalization at Home: a global perspective. (pp. 54-55). The Hague: Nuffic.

[8] SUNY Cortland. N.d. Faculty Guide for Collaborative Online International Learning. SUNY COIL Center. Cortland: New York. Retrieved from: http://www.ufic.ufl.edu/UAP/Forms/COIL_guide.pdf 
[9] Marton, F., \& Booth, S. (1997). Learning and awareness. Ilha Do Desterro, (38), 177-182.

[10] Niehaus, E. \& Williams, L. (2016). Faculty Transformation in Curriculum Transformation: The role of faculty development in campus internationalization. Springer. New York. 41: 59. https://doiorg.proxy.bc.edu/10.1007/s10755-015-9334-7

[11] Jones, E. (2017). Internationlisation of the Curriculum: Challenges, Misconceptions and the Role of Disciplines taken from Internationlisierung der Curricula an Hochschulen. pp.24. Wbv. Germany.

[12] HRK. (2018). HRK-Expertise Internationalisation. Retrieved from: https://www.hrk.de/fileadmin/redaktion/ hrk-expertise/Fact_Sheet_EXPERTISE_Englisch.pdf 